\title{
Papers
}

\section{Downsizing of acute inpatient beds associated with private finance initiative: Scotland's case study}

\author{
Matthew G Dunnigan, Allyson M Pollock
}

\begin{abstract}
Objectives To evaluate whether the projected 24\% reduction in acute bed numbers in Lothian hospitals, which formed part of the private finance initiative (PFI) plans for the replacement Royal Infirmary of Edinburgh, is being compensated for by improvements in efficiency and greater use of community facilities, and to ascertain whether there is an independent PFI effect by comparing clinical activity and performance in acute specialties in Lothian hospitals with other NHS hospitals in Scotland.

Design Comparison of projected and actual trends in acute bed capacity and inpatient and day case admissions in the first five years (1995-6 to 2000-1) of Lothian Health Board's integrated healthcare plan. Population study of trends in bed rate, hospital activity, length of stay, and throughput in Lothian hospitals compared with the rest of Scotland from 1990-1 to 2000-1.
\end{abstract}

Main outcome measures Staffed bed rates, admission rates, mean lengths of stay, occupancy, and throughput in four adult acute specialty groups in 1990-1, 1995-6, and 2000-1.

Results By 2000-1, rates for inpatient admission in all acute, medical, surgical, and intensive therapy specialties in Lothian hospitals were respectively $20 \%$, $6 \%, 28 \%$, and $38 \%$ below those in the rest of Scotland. Day case rates in all acute and acute surgical specialties were 13\% and 33\% lower. The proportion of delayed discharges in staffed acute and post-acute NHS beds in Lothian hospitals exceeded the Scottish average $(15 \%$ and $12 \%$ respectively; $\mathrm{P}<0.001)$.

Conclusion The planning targets and increase in clinical activity in acute specialties in Lothian hospitals associated with PFI had not been achieved by $2000-1$. The effect on clinical activity has been a steeper decline in the number of acute beds and rates of admission in Lothian hospitals compared with the rest of Scotland between 1995-6 and 2000-1.

\section{Introduction}

The use of the private finance initiative (PFI) in new replacement NHS hospitals is associated with substantial reductions in the number of beds across the areas in which the hospitals are located. The full business cases for the 15 first wave PFI hospitals in England and Scotland projected reductions in acute beds of about
$30 \%$ (median 29\%; range 5-44\%) in the five or so years before the new hospitals would be opened. ${ }^{12}$ These reductions were based on anticipated improvements in service efficiency, including shorter lengths of stay, earlier discharge from acute beds, and greater use of community facilities. Although many of the first wave PFI hospitals have now opened, there has been no evaluation of their planning assumptions or of whether the benefits of the new investment have been realised through increased efficiency.

The new Royal Infirmary of Edinburgh, the most costly first wave acute hospital funded by PFI, is an exemplar of the planning assumptions involved in most first wave PFI projects. The new PFI hospital formed the cornerstone of Lothian Health Board's 1996 integrated healthcare plan (IHCP). The original plan, which projected a reduction in total acute bed capacity across Lothian of 28\% (from 2093 to 1513 beds) from 1995-6 to 2002-3, was revised in 2000 to $24 \%{ }^{3}{ }^{4}$ This revised reduction was based on the new PFI hospital having 10\% (774 to 695) fewer adult acute beds than its predecessor, the closure of five acute hospitals, and reductions in bed numbers in the three remaining acute hospitals.

We evaluated whether the plan's targets for service delivery were fulfilled at the end of the first five years of implementation and established whether there was a "PFI effect" by comparing the impact of acute bed closures in Lothian and other Scottish NHS hospitals on clinical activity between 1990-1 and 2000-1. We also examined whether financial constraints contributed to the determination of targets for acute bed reductions in Lothian hospitals before and during implementation of the healthcare plan.

\section{Methods}

Sources of data-Lothian's planning targets for changes in bed numbers and inpatient and day case admissions from 1995-6 to 2002-3 were supplied by Lothian Health Board. ${ }^{4}$ Actual data on annual clinical activity, admissions, bed occupancy, throughput, and length of stay for 1990-1 to 2000-1 were supplied by the information and statistics division of the NHS in Scotland (ISD Scotland). We categorised clinical activity into five adult specialty groups: all acute, acute medical, acute surgical, intensive therapy (intensive and cardiac care units), and geriatric (assessment and long stay). ${ }^{5}$ The general register office, Scotland, provided
University

Department of

Human Nutrition,

Glasgow Royal

Infirmary, Glasgow

G31 2ER

Matthew G

Dunnigan

senior research fellow

Public Health Policy

Unit, School of

Public Policy,

University College

London, London

WC1H 9QU

Allyson M Pollock

professor

Correspondence to:

A M Pollock

allyson.pollock@

ucl.ac.uk

bmj.com 2003;326:905 
estimated midyear populations for Lothian health board and the rest of Scotland. In June 1995, the estimated catchment population of Lothian health board was 764600 and was 4372000 for the rest of Scotland. Their demographic structures are similar with estimated proportions of men and women aged over 75 years in 1995 of $6.3 \%$ and $6.4 \%$ respectively.

Analysis and statistical methods-We compared changes in the number of hospital beds and inpatient and day case admissions to Lothian hospitals from 1995-6 and 2000-1 with the 2002-3 targets in the healthcare plan. We calculated staffed bed and admission rates per 1000 resident population for the five specialties for Lothian and other Scottish NHS hospitals for the years 1990-1, 1995-6, and 2000-1. Mean length of stay, occupancy, and throughput were calculated by specialty for Lothian and other Scottish NHS hospitals. We used square root transformation to calculate confidence intervals $(95 \%, 99 \%$, and 99.9\%) for admission rates. ${ }^{6}$ Differences in admission rates that exceeded these confidence intervals were assigned appropriate significance values. Relative admission rates for acute specialties indicate the percentages by which Lothian (L) rates exceeded or fell below rates in other Scottish (S) NHS hospitals in 1990-1, 1995-6, and 2000-1 (L/S\% - 100; figs 1 and 2).

Integrated healthcare plan's planning targets-Table 1 shows the comparison of the healthcare plan targets for adult staffed beds and inpatients and day cases in acute and post-acute specialties from 1995-6 to 2002-3 with actual performance to 2000-1. No targets were available for admissions to geriatric specialties or for numbers of beds in private nursing homes. The planning projections assumed that reductions in acute beds would be compensated for by continuing reductions in lengths of stay in acute specialties; an

Table 1 Staffed bed and admission targets contained in Lothian Health Board's integrated healthcare plan (1995-6 to 2002-3) compared with performance between 1995-6 and 2000-1*

\begin{tabular}{lrrr} 
& \multicolumn{2}{c}{ Performance } & \\
\cline { 2 - 3 } Specialty groups & $\mathbf{1 9 9 5 - 6}$ & $\mathbf{2 0 0 0 - 1}$ & \\
\hline Staffed beds & & & Target† 2002-3 \\
\hline Acute specialties: & & & \\
\hline All acute & 2093 & 1684 & 1585 \\
\hline Acute medical§ & 757 & 629 & 620 \\
\hline Acute surgicalf & 813 & 632 & 574 \\
\hline Post-acute specialties: & & & 646 \\
\hline Geriatric assessment & 661 & 658 & NA \\
\hline Geriatric long stay & 805 & 441 & \\
\hline
\end{tabular}

Inpatients and day cases

Acute specialties:

\begin{tabular}{lrrc}
\hline \multicolumn{1}{c}{ All acuteł } & 158035 & 158495 & 190998 \\
\hline Acute medical§ & 56690 & 66126 & 86153 \\
\hline Acute surgicalf & 74894 & 65141 & 80890 \\
\hline Post-acute specialties: & & & NA \\
\hline Geriatric assessment & 7419 & 5889 & NA \\
\hline Geriatric long stay & 958 & 1145 & \\
\hline
\end{tabular}

*Data derived from forms ISD(S)1, SMR1, and SMR01; information and statistics department, NHS in Scotland

†Projected 2002-3 acute bed numbers and inpatient and day case discharges, Lothian Health Board, 1999; updated 2000 (bed numbers only).

$\ddagger$ Acute medical, acute surgical, and intensive therapy specialties, tertiary specialties (neurology,

neurosurgery, cardiothoracic surgery, plastic surgery, and radiotherapy), communicable diseases, and the accident and emergency specialty.

$\S$ General medicine, cardiology, gastroenterology, haematology, nephrology, medical oncology, metabolic disease, rheumatology, respiratory disease, and rehabilitation medicine.

IGeneral surgery, orthopaedic surgery, otorhinolaryngology, ophthalmology, urology, gynaecology, and oral surgery and medicine. increasing proportion of surgical procedures undertaken on a day case basis; improved community facilities to reduce the need for hospital admission and improve the effectiveness of hospital discharge; and the provision of traditional hospital services in new more accessible settings such as community treatment centres. ${ }^{4}$ We used the actual data to examine these claims for the first five years of the healthcare plan.

\section{Results}

Comparisons between 1995-6 and 2000-1 for

Lothian against healthcare plan targets

Bed targets-By 2000-1, 81\% (409 of 508) of the reductions in acute beds that Lothian health board planned for by 2002-3 had been achieved (table 1).

Inpatient and day case admissions-The healthcare plan projected an increase of 21\% (158035 to $190998)$ in admissions to all acute specialties. By 2000-1 the actual increase was $0.3 \%$ (158035 to 158495 ). Inpatient admissions to surgical specialities were projected to rise by $8 \%$; actual admissions fell by 13\% (74 894 to 65141 ) (table 1).

Reduced length of stay-Despite predictions that length of stay would fall, this happened only in medical specialties; length of stay increased in surgical specialties, intensive therapy, and geriatric assessment (table 2). The total reduction across all acute specialties was 0.1 days.

Surgical day cases-The healthcare plan projected a switch from inpatient to day case surgery. There was a $22 \%$ (from 55 to 43 ) fall in inpatient surgical admission rates (table 3). Surgical day case admission rates fell by $3.3 \%$ (30 to 29) over the same period.

Community facilities: the planned expansion-The number of private nursing home beds in Lothian fell by $7 \%$ (from 3157 to 2935) compared with a $7 \%$ rise (from 18609 to 19 947) in the rest of Scotland. The number of long stay NHS geriatric beds fell by $45 \%$ (from 805 to 441) compared with a 40\% (5333 to 3204) reduction in the rest of Scotland. In January 2002, the proportion of delayed discharges in beds in acute and post-acute NHS specialties in Lothian hospitals was significantly higher than the Scottish average $(15 \%$; $543 / 3596$ v $12 \%$; $3116 / 25$ 752; $\mathrm{P}<0.001)$.

New care settings-The healthcare plan anticipated an expansion in community provision. However, no community treatment centres were opened in Lothian. Acute inpatient care in the private sector in Scotland remains rare. In Edinburgh, one private hospital provided 69 inpatient and day case beds in 2000-1 compared with 70 in 1995-6. A considerable transfer of elective surgery to this setting is unlikely.

\section{Clinical activity between 1990-1 and 2000-1}

Staffed bed rates-The number of staffed beds per 1000 resident population in all acute specialties in Lothian hospitals fell at twice the rate seen in other Scottish NHS hospitals (table 4). By 2000-1, staffed bed rates in all acute, medical, surgical, and intensive therapy specialties in Lothian hospitals, respectively, were $30 \%$ ( $1.9 v 2.7), 23 \%$ ( $0.76 v 0.99$ ), 33\% (0.74 v 1.1), and $27 \%(4.6 v 6.3 / 100000)$ below those in the rest of Scotland. Staffed bed rates in geriatric assessment in the Lothian hospitals fell from $35 \%(0.66 v 0.49)$ to $27 \%$ (0.84 v 0.66) above the rest of Scotland. 
Inpatient admission rates-All differences in inpatient and day case admission rates between Lothian and other Scottish NHS hospitals were significant. Between 1990-1 and 1995-6, inpatient admission rates in all acute specialties in Lothian and other Scottish NHS hospitals rose by $2.6 \%$ (115 to 118 ) and $6.4 \%$ (124 to 132) respectively (table 3 , fig 1 ). In contrast, during the first five years of the healthcare plan the admission rate in acute specialties in Lothian hospitals fell by $11 \%$ (118 to 105) compared with a $0.8 \%$ (132 to 131 ) decline in other Scottish NHS hospitals. By 2000-1, inpatient admission rates in all acute, medical, surgical, and intensive therapy specialties in Lothian hospitals were respectively 20\% (105 v 131), 6.3\% (45 v 48), 28\%
(43 $v 60)$, and 38\% (3.8 $v 6.1)$ below those in other Scottish NHS hospitals. Elective admission rates were proportionately lower in all acute, medical, and surgical specialties.

Day case admission rates-Between 1990-1 and 2000-1, day case admission rates in all acute specialties in Scottish NHS hospitals (excluding Lothian hospitals) rose by $152 \%$ (31 to 78 ) (table 3 , fig 2 ). Rates in Lothian hospitals rose by $100 \%$ (34 to 68 ) over this period, mainly reflecting a fivefold rise in acute medical specialties. Between 1990-1 and 1995-6 day case rates in surgical specialties rose by $15 \%$ (26 to 30$)$ and fell by $3.3 \%$ (30 to 29) during the first five years of the healthcare plan (1995-96 and 2000-1). By 2000-1, day case

Table 2 Mean stay, occupancy, and throughput in Lothian Health Board (L) and other Scottish NHS hospitals (S), 1990-1 to 2000-1

\begin{tabular}{|c|c|c|c|c|c|c|c|c|c|c|}
\hline \multirow[b]{3}{*}{ Specialty groups } & \multicolumn{6}{|c|}{ Performance } & \multicolumn{4}{|c|}{ Percentage change } \\
\hline & \multicolumn{2}{|c|}{ 1990-91 } & \multicolumn{2}{|c|}{ 1995-96 } & \multicolumn{2}{|c|}{$2000-01$} & \multicolumn{2}{|c|}{$1990-91$ to $1995-96$} & \multicolumn{2}{|c|}{$1995-96$ to $2000-01$} \\
\hline & L & S & $\mathbf{L}$ & S & $\mathbf{L}$ & S & L & S & $\mathbf{L}$ & $S$ \\
\hline \multicolumn{11}{|l|}{ Mean stay $\left(\right.$ days) ${ }^{*}$ : } \\
\hline All acute & 7.4 & 7.0 & 5.8 & 6.1 & 5.7 & 5.9 & -22 & -13 & -1.7 & -3.3 \\
\hline Acute medical & 8.9 & 8.8 & 6.6 & 7.0 & 5.5 & 6.6 & -26 & -20 & -17 & -5.7 \\
\hline Acute surgical & 5.9 & 6.1 & 4.6 & 5.1 & 5.0 & 4.9 & -22 & -16 & 8.6 & -3.9 \\
\hline Intensive therapy $\dagger$ & 2.2 & 2.6 & 2.6 & 2.7 & 3.2 & 2.7 & 18 & 3.8 & 23 & 0 \\
\hline Geriatric assessment & 31 & 35 & 29 & 28 & 31 & 29 & -6.5 & -20 & 6.8 & 3.5 \\
\hline \multicolumn{11}{|l|}{ Occupancy (\%)‡: } \\
\hline All acute† & 75 & 72 & 77 & 74 & 85 & 79 & 2.6 & 2.8 & 10 & 6.7 \\
\hline Acute medical $\ddagger$ & 84 & 80 & 88 & 83 & 90 & 87 & 4.8 & 3.8 & 2.3 & 4.8 \\
\hline Acute surgical§ & 69 & 68 & 70 & 70 & 81 & 74 & 1.4 & 2.9 & 16 & 5.7 \\
\hline Intensive therapy† & 70 & 67 & 69 & 69 & 74 & 71 & -1.4 & 3.0 & 7.2 & 2.9 \\
\hline Geriatric assessment & 86 & 88 & 89 & 88 & 94 & 91 & 3.4 & 0 & 5.6 & 3.4 \\
\hline \multicolumn{11}{|l|}{ Throughput§: } \\
\hline All acute & 37 & 37 & 48 & 45 & 54 & 48 & 30 & 22 & 13 & 6.7 \\
\hline Acute medical & 34 & 33 & 49 & 43 & 60 & 48 & 44 & 30 & 22 & 12 \\
\hline Acute surgical & 42 & 41 & 56 & 50 & 59 & 55 & 33 & 22 & 5.4 & 10 \\
\hline Intensive therapy† & 116 & 94 & 96 & 93 & 84 & 96 & -17 & -1.1 & -13 & 3.2 \\
\hline Geriatric assessment & 10 & 9 & 11 & 11 & 11 & 11 & 10 & 22 & 0 & 0 \\
\hline
\end{tabular}

*Excludes transfers out (except intensive therapy units).

†Intensive care and cardiac care units.

$\neq$ Occupied bed days as percentage of available bed days.

§Admissions per staffed bed per year, excluding transfers out (except intensive therapy units).

Table 3 Inpatient and day admission rates in Lothian Health Board (L) and other Scottish NHS hospitals (S), 1990-1 to 2000-1

\begin{tabular}{|c|c|c|c|c|c|c|c|c|c|c|c|c|c|}
\hline \multirow[b]{3}{*}{ Specialty groups } & \multicolumn{9}{|c|}{ Admission ratest (per 1000 population) } & \multicolumn{4}{|c|}{ Percentage change } \\
\hline & \multicolumn{3}{|c|}{$1990-1$} & \multicolumn{3}{|c|}{ 1995-6 } & \multicolumn{3}{|c|}{$2000-1$} & \multicolumn{2}{|c|}{$1990-1$ to $1995-6$} & \multicolumn{2}{|c|}{$1995-6$ to $2000-1$} \\
\hline & L & $\mathbf{S}$ & $\begin{array}{c}P \\
\text { value }\end{array}$ & L & S & $\begin{array}{c}P \\
\text { value }\end{array}$ & L & $S$ & $\begin{array}{c}P \\
\text { value }\end{array}$ & L & S & L & S \\
\hline \multicolumn{14}{|l|}{ Inpatient: } \\
\hline All acute & 115 & 124 & $\star \star \star \star$ & 118 & 132 & 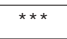 & 105 & 131 & $\star \star \star \star$ & 2.6 & 6.4 & -11 & -0.8 \\
\hline Acute medical & 38 & 35 & 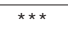 & 44 & 43 & ** & 45 & 48 & $\star \star \star *$ & 16 & 23 & 2.3 & 12 \\
\hline Acute surgical & 60 & 70 & $\star \star \star *$ & 55 & 67 & $\star \star \star *$ & 43 & 60 & $\star \star \star *$ & -8.3 & -4.3 & -22 & -10 \\
\hline Intensive therapy & 3.9 & 3.4 & $\star \star \star *$ & 4.2 & 4.5 & * & 3.8 & 6.1 & $* \star *$ & 7.6 & 32 & -10 & 36 \\
\hline $\begin{array}{l}\text { Geriatric } \\
\text { assessment }\end{array}$ & 6.5 & 4.5 & $\star * *$ & 9.6 & 7.1 & $\star \star \star *$ & 8.5 & 7.7 & $\star * \star *$ & 48 & 58 & -11 & 8.5 \\
\hline \multicolumn{14}{|l|}{ Emergency: } \\
\hline All acute & 66 & 67 & * & 75 & 78 & 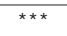 & 75 & 88 & $\star * *$ & 14 & 16 & 0 & 13 \\
\hline Acute medical & 31 & 27 & $\star \star \star *$ & 38 & 35 & $\star \star \star *$ & 40 & 41 & ** & 23 & 30 & 5.2 & 17 \\
\hline Acute surgical & 25 & 27 & $\star \star * *$ & 25 & 29 & $\star \star \star *$ & 23 & 30 & $\star * *$ & 0 & 7.4 & -8.0 & 3.4 \\
\hline \multicolumn{14}{|l|}{ Elective: } \\
\hline All acute & 49 & 58 & $\star \star \star \star$ & 43 & 53 & $\star \star \star$ & 30 & 44 & $\star \star \star \star$ & -12 & -8.6 & -30 & -17 \\
\hline Acute medical & 7.0 & 8.2 & 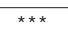 & 6.4 & 8.0 & $\star \star \star *$ & 5.0 & 6.9 & $* * *$ & -8.6 & -2.4 & -22 & -14 \\
\hline Acute surgical & 35 & 44 & $\star \star \star *$ & 30 & 38 & $\star \star \star *$ & 20 & 30 & $\star \star \star \star$ & -14 & -14 & -33 & -21 \\
\hline \multicolumn{14}{|l|}{ Day case: } \\
\hline All acute & 34 & 31 & $\star \star \star *$ & 58 & 60 & $\star * \star$ & 68 & 78 & $* * *$ & 71 & 94 & 17 & 30 \\
\hline Acute medical & 5.3 & 5.9 & $\star \star \star \star$ & 22 & 17 & $\star \star \star *$ & 30 & 26 & $\star \star \star \star$ & 315 & 188 & 36 & 53 \\
\hline Acute surgical & 26 & 18 & $\star \star \star *$ & 30 & 38 & $\star \star \star *$ & 29 & 43 & $\star * \star$ & 15 & 111 & -3.3 & 13 \\
\hline
\end{tabular}

Significance of differences between admission rates in Lothian Health Board and other Scottish NHS hospitals: ${ }^{*} \mathrm{P}<0.05 ;{ }^{* *} \mathrm{P}<0.01 ;{ }^{* * *} \mathrm{P}<0.001$.

†Per 1000 estimated midyear resident populations of Lothian and rest of Scotland, excluding transfers out (except intensive therapy units). 
Table 4 Staffed bed rates in acute specialties in Lothian Health Board (L) and other Scottish NHS hospitals (S), 1990-1 to 2000-1, expressed as staffed beds per 1000 resident populations

\begin{tabular}{|c|c|c|c|c|c|c|c|c|c|c|}
\hline \multirow[b]{3}{*}{ Specialty groups } & \multicolumn{6}{|c|}{ Staffed bed rates* (per 1000 population) } & \multicolumn{4}{|c|}{ Percentage change } \\
\hline & \multicolumn{2}{|c|}{ 1990-1 } & \multicolumn{2}{|c|}{ 1995-6 } & \multicolumn{2}{|c|}{$2000-1$} & \multicolumn{2}{|c|}{$1990-1$ to $1995-6$} & \multicolumn{2}{|c|}{$1995-6$ to $2000-1$} \\
\hline & $\mathbf{L}$ & S & $\mathbf{L}$ & S & $\mathbf{L}$ & S & $\mathbf{L}$ & S & $\mathbf{L}$ & S \\
\hline All acute & 3.1 & 3.3 & 2.4 & 3.0 & 1.9 & 2.7 & -23 & -9.1 & -21 & -10 \\
\hline Acute medical & 1.1 & 1.1 & 0.9 & 1.0 & 0.76 & 0.99 & -18 & -9.1 & -16 & -1.0 \\
\hline Acute surgical & 1.4 & 1.7 & 0.97 & 1.3 & 0.74 & 1.1 & -31 & -24 & -24 & -15 \\
\hline Intensive therapy & 3.3 & 3.7 & 4.4 & 4.8 & 4.6 & 6.3 & 33 & 30 & 4.5 & 31 \\
\hline Geriatric assessment & 0.66 & 0.49 & 0.86 & 0.68 & 0.84 & 0.66 & 30 & 39 & -2.3 & -2.9 \\
\hline
\end{tabular}

*Per 100000 estimated midyear resident populations of Lothian and rest of Scotland.

admission rates in Lothian hospitals in all acute and surgical specialties were respectively $13 \%(68 v 78)$ and 33\% (29 $v 43)$ below those in other Scottish NHS hospitals.

Trends in performance-Between 1990-1 and 1995-6, mean length of stay (days) in all acute specialties in Lothian and other Scottish NHS hospitals fell by $22 \%$ (7.4 to 5.8 ) and $13 \%$ (7.0 to 6.1 ) respectively (table 2 ). Similar reductions occurred in acute medical and surgical specialties. However, between 1995-6 and 2000-1, mean length of stay fell by $1.7 \%$ (5.8 to 5.7 ) and 3.3\% (6.1 to 5.9) respectively. In surgical and intensive therapy specialties mean length of stay rose by $8.7 \%$ (4.6 to 5.0) and 23\% (2.6 to 3.2) in Lothian hospitals compared with a fall of $3.9 \%$ (5.1 to 4.9 ) and no change (2.7 to 2.7) in the rest of Scotland. Occupancy remained stable in acute specialties in Scottish NHS hospitals between 1990-1 and 1995-6 and rose by 10\%

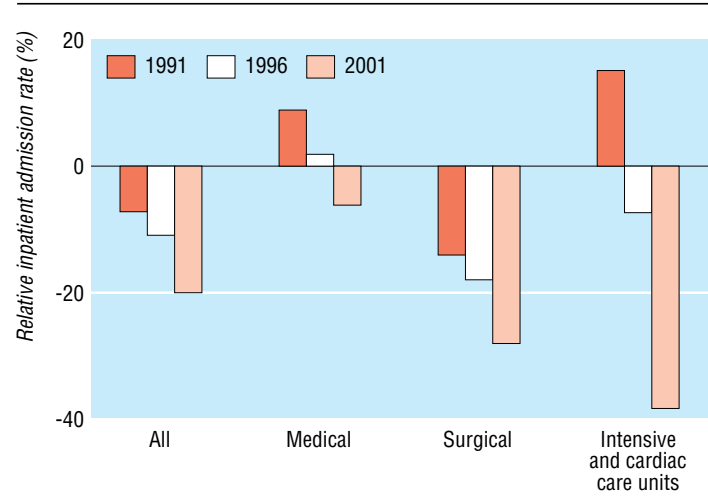

Fig 1 Relative inpatient admission rates in acute specialties in Lothian (L) compared with Scottish (S) NHS hospitals in 1990-1, 1995-6, and 2000-1 (L/S-100)

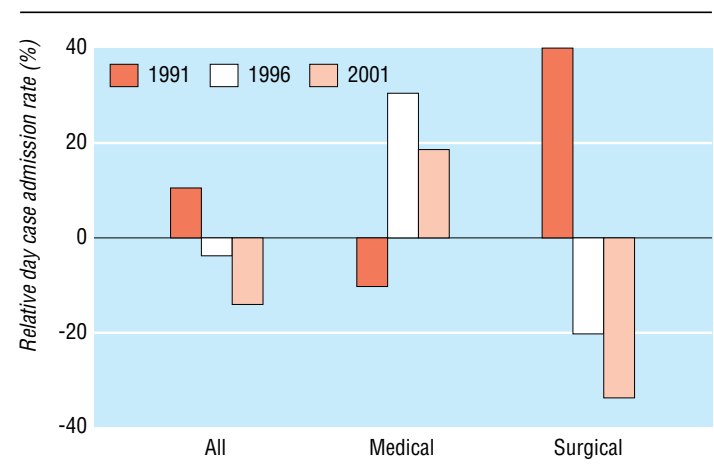

Fig 2 Relative day case admission rates in acute specialties in Lothian (L) compared with Scottish (S) NHS hospitals in 1990-1, 1995-6, and 2000-1 (L/S-100) between 1995-6 and 2000-1 after the onset of capacity constraints. Occupancy levels were higher in Lothian than in other Scottish NHS hospitals by 2000-1 (table 2). Throughput per staffed acute bed in all acute, medi$\mathrm{cal}$, and surgical specialties rose by $46 \%, 76 \%$, and $40 \%$, respectively, in Lothian hospitals compared with 30\%, $45 \%$, and 34\% in the rest of Scotland between 1990-1 and 2000-1.

\section{Discussion}

\section{Planning targets for Lothian's healthcare plan}

Our evaluation of the service plans underpinning the planned reductions in acute beds in Lothian hospitals associated with a major PFI hospital development shows that, while by 2001 most $(80 \%)$ of the bed closures planned across Lothian had been achieved, the service was unable to accommodate the projected increase in hospital admissions due to severe constraints in capacity. ${ }^{34}$ By 2000-1 inpatient and day case admissions in all acute specialties rose by only $3 \%$ compared with a projected increase of $21 \%$ by $2002-3$, while admissions to surgical specialties fell by $13 \%$ compared with a projected increase of $8 \%$. Capacity constraints that prevented increases in hospital admissions were the result of length of stay remaining static in acute specialties and increasing across surgical, intensive therapy, and geriatric assessment specialties. The increase in length of stay in acute surgical and intensive therapy specialties suggests a rising threshold for admission, with greater morbidity among those admitted-that is, sicker patients are admitted.

The service plans did not result in an expansion of community provision as intended, and long stay geriatric beds and private nursing home beds continued to close over this period. The lack of capacity in the community is evident in the proportion of delayed discharges in Lothian hospitals (mainly in long stay NHS beds), which rose significantly above the Scottish average and contributed to the failure to secure further reductions in length of stay in hospital across all acute specialties.

Until the publication of the national beds inquiry for England in 2000, the general consensus was that further NHS bed reductions could be achieved by improvements in performance. ${ }^{7}$ Management consultants, the National Association of Health Authorities and Trusts, the Scottish Health Executive, and the Department of Health justified 30\% reductions in NHS acute bed capacity in PFI hospital developments by the early years of the 21 st century on the basis of previous trends in beds, admissions, and length of stay. ${ }^{12}{ }^{8-11}$ It is notable that at no time in the history of the NHS have acute bed closures approached 30\% over a five year 
period. By the time the national beds inquiry for England had overturned the consensus on bed closures, stating that further bed closures could not safely be achieved, many of the PFI hospital plans had been signed off and some were in serious financial difficulty. ${ }^{12}$

\section{Is there a PFI effect?}

Ministers and civil servants have been unanimous in stating that bed closures are a result of clinical decision making and are independent of the affordability problems created by PFI. ${ }^{13}$ Indeed the former Scottish health minister, Sam Galbraith, maintained that clinicians not only agreed but decided bed reductions. ${ }^{14}$ This has been contested by clinicians involved in the preparation of the activity projections of the healthcare plan, who state that bed numbers were determined by the Scottish management executive on the grounds of affordability while clinicians allocated beds to individual specialities within a predetermined total. ${ }^{15} 16$

Our study provides compelling evidence of an independent PFI effect on hospital downsizing by comparing hospital bed rates, admissions, and data on length of stay between Lothian and other Scottish hospitals. Further evidence comes from comparing bed numbers in Scottish NHS boards with and without PFI hospital developments. In Lothian and Lanarkshire Health Boards (both associated with PFI hospital projects), acute bed numbers fell by 20\% (from 2093 to 1684 ) and $14 \%$ (1357 to 1167 ) respectively between 1995-6 and 2000-1 compared with 7.8\% (11308 to 10428 ) in Scotland's 13 remaining health boards. ${ }^{8}$

\section{Evidence for financial constraints}

Financial evaluation of PFI hospital projects has exposed the degree to which financial constraints restrict capital investment and make new claims on the revenue budget. ${ }^{17-19}$ In our study the reduction in admission rates in Lothian compared with other Scottish NHS hospitals reflects the difference between severe capacity constraints associated with a large PFI project and moderate pressures for efficiency savings as a result of underfunding in 13 of the 15 other Scottish Health Boards without PFI projects for new hospitals.

Further direct evidence of financial problems comes from the planning documents for PFI hospitals. In 1992, Lothian Health Board's acute services strategy projected a $13 \%$ reduction in adult acute beds (from 2312 to 2003) in Lothian hospitals between 1991-2 and 2001-2. ${ }^{20}$ In August 1992, a memorandum from the Scottish Executive to Lothian Health Board stated that "the accumulation of evidence does suggest ... that it is reasonable to look for substantial reductions in bed requirements over the next 10-15 years" and that "the overriding requirement is of course to develop a strategy which is affordable in revenue terms ... For this reason it is necessary to reconsider whether the cost of the acute strategy could be cut back by reducing the number of inpatient beds" (A Munro, memo to Lothian Health Board, August 1992). By 1996, the 1992 strategy had been superseded by the integrated healthcare plan. Strongly influenced by affordability constraints, this reduced the previous targets for acute beds by almost a quarter (24\%; 490 beds). Similar financial constraints resulting in revisions to bed numbers were experienced in planning first wave
PFI hospitals in Halifax, Hereford, Worcester, and Norfolk and Norwich. ${ }^{21}$

The healthcare plan anticipated that bed closures and the new PFI scheme would generate a 9\% (£15m) reduction in real terms in revenue expenditure on acute hospital services, which could be reinvested in other service programmes. ${ }^{3}$ As our evaluation has shown, the service expansion in the post-acute community sector did not occur.

Despite the major downsizing of hospital beds, the Lothian University Hospitals NHS Trust continues to face serious financial problems. In January 2003, the report of the auditor general for Scotland highlighted a deficit requiring annual recurrent savings of $£ 25.6 \mathrm{~m}$ by $2006-7 .{ }^{22}$ In 2001, the Lothian-wide review team had estimated a shortfall of income and expenditure of $£ 95 \mathrm{~m}$ over the four year period 2002-3 to 2005-6, associated with five key business cases including the new PFI. The financial recovery plan to address this shortfall expects that $£ 55 \mathrm{~m}$ of savings will come from sale of land and estate and a further $£ 40 \mathrm{~m}$ from savings in the redesign of acute and primary care services. But the auditor general notes that the "external auditor however considers there is a risk that the financial plan may not be deliverable and therefore the potential deficit may exceed the levels projected." If this is the case further services may have to close, compounding the severe capacity constraints. Alternatively Lothian may have to be bailed out at the expense of the rest of the NHS in Scotland.

In England, district auditors have reported on the financial and clinical performance of other downsized PFI hospitals. A report on a new PFI hospital in North Durham states that the trust is at a high risk of failing to meet inpatient targets "especially in respect of patient access" (NHS plan implementation programme review. North Durham Healthcare NHS Trust. Audit District Audit 2000-1) ${ }^{23}$ For Halifax PFI hospital the auditor expressed concerns about severe pressure on beds, high occupancy levels, a rapid increase in waiting lists and outpatient waiting times, and cancelled elective operations (annual audit letter, Calderdale Healthcare NHS Trust, district audit 2000-1). A report on a new PFI hospital in Worcester identified financial deficits and severe capacity pressures on available beds from emergency admissions with high occupancy, the decanting of patients to inappropriate specialty beds, and an unacceptably high number of patients with nine and 12 month waiting times (annual audit letter, Worcestershire Acute Hospitals NHS Trust, district audit 2001-2).

\section{Conclusion}

The public accounts committee, the health select committee, and the BMA have called for independent evaluations of new PFI hospitals. Financial and district auditor's reports are the first hard evidence of the scale of capacity constraints and financial problems facing new downsized PFI hospitals. Our analysis shows evidence of reduced service delivery across Lothian and its associated PFI development compared with other Scottish NHS hospitals. There is evidence of both an independent "PFI effect" and of a capacity ceiling in acute specialties and a need for further expansion in acute and community provision. New financial evidence suggests that further hospital and 


\section{What is already known on this topic}

The full business cases for the 15 first wave private finance initiative (PFI) hospitals in England and Scotland projected reductions in acute beds of about $30 \%$ in the five years before the opening of the new replacement hospitals

The new PFI Royal Infirmary of Edinburgh, which will fully open in 2003, is the cornerstone of Lothian Health Board's healthcare plan for its acute hospitals

\section{What this study adds}

Compared with other Scottish NHS hospitals, service delivery has been reduced across Lothian associated with PFI development

The planning targets and increase in clinical activity in acute specialties in Lothian hospitals had not been achieved by 2000-1

There is evidence of an independent "PFI effect" on hospital downsizing and bed reductions, which in Lothian has resulted in severe capacity constraints across all acute specialties with a need for immediate expansion in acute and community provision

Further hospital and community service downsizing may be required to meet the financial deficit, which is principally due to the high costs of PFI

community service downsizing, over and above the $24 \%$ reduction in beds and associated services, may be required to meet the financial deficit, principally due to the high costs of PFI. Further post-implementation analyses are required of the consequences of downsizing NHS acute capacity on clinical activity and access to care in "the largest hospital building programme in the history of the NHS."

We thank Trevor Jones and Harry Purser (Lothian Health Board) and the information and statistics division, Scotland, for data; and Brian Potter for helpful advice.

Contributors: MD carried out research and analysis. MD and AMP designed the study and wrote the paper. AMP is guarantor. Funding: No funding was received for this article. The Public Health Policy Unit has received grants and contributions towards some evaluations of PFI schemes from the BMA, the NHS Consultants' Association, UNISON, a health authority, and local authorities. The guarantor accepts full responsibility for the conduct of the study, had access to the data, and controlled the decision to publish.

Competing interests: None declared.

1 Pollock AM, Dunnigan MG, Gaffney D, Macfarlane A, Majeed FA. What happens when the private sector plans hospital services for the NHS: three case studies under the private finance initiative. $B M$ J 1997;314:1266-71.

2 Pollock AM, Dunnigan MG, Gaffney D, Price D, Shaoul J. Planning the "new" NHS: downsizing for the 21st century. BMJ 1999:319:179-84

3 Lothian Health Board. Integrated healthcare plan 1996-2003. Edinburgh: Lothian Health Board, 1996.

4 Lothian Health Board. Integrated healthcare plan 1996-2003. Review of projected 2002-03 projected acute bed numbers, inpatient discharges, and inpatien and day case discharges. Edinburgh: Lothian Health Board, 1999 (updated 2000).

5 Dunnigan MG. The downsized hospital hypothesis: value for money? The results of reducing staffed bed capacity on clinical activity in Lothian Health Board and other Scottish NHS hospitals between 1991 and 2000. Part One: Sections one to nine; Part Two: Tables. Edinburgh: Nationa Health Service Consultants Association, 2001. www.ucl.ac.uk/spp/about/ health policy/lothian report.php (accessed $10 \mathrm{Apr} 2003$ ).

6 Breslow NE, Day NE. Statistical methods in cancer research. Vol II. The desion and analysis of cohort studies. Lyons: International Agency for Research on Cancer, 1987 .

7 Department of Health. Shaping the future NHS: long term planning for hos pitals and related services. Consultation document on the findings of the nationa beds inquiry. London: Department of Health, 2000.

8 Manchester Health Services Management Unit. The future healthcare work force. The steering group report. Manchester: University of Manchester, 1996.

9 Warner M, Riley C. Closer to home. Healthcare in the 21st century. Welsh Association of Health Authorities and Trusts, 1994:1-50. (Research paper 13.)

10 Scaife G. Accountability reviews. Priorities and planning guidance for 1994-95. NHS in Scotland [annex B]. Edinburgh: Management Executive, 1993

11 Munro A. Requirement for acute beds in Scotland: the past and the future. Health Bulletin 1994;52:35-47.

12 Pollock AM, Dunnigan M. Beds in the NHS: the national beds inquiry exposes a contradiction at the heart of government health policy. $B M J$ 2000;320:461-2

13 Coates P. Don't shoot the messenger. Public Finance 2000 August 25;16-9. 14 Galbraith S. The public sector decides. Herald 1999 Feb 20.

5 Rhind G. [Letter.] Herald 1999 February 23.

16 Dunnigan MG. Private finance initiative. Bed numbers were imposed. Herald 1999 March 1.

17 Gaffney D, Pollock AM, Price D, Shaoul J. NHS capital expenditure and the private finance initiative-expansion or contraction? $B M J$ 1999:319:48-51.

18 Gaffney D, Pollock AM, Price D, Shaoul J. PFI in the NHS-is there an economic case? BMJ 1999;319:116-9.

19 Gaffney D, Pollock AM, Price D, Shaoul J. The politics of the private finance initiative and the new NHS. BMJ 1999;319:249-53.

20 Lothian Health. Acute services strategy. Professional consultancy document. Edinburgh: Lothian Health Board, 1992.

21 Smith CA. Making sense of the private finance initiative. Abingdon: Radcliffe Medical Press, 1999:140.

22 Auditor General for Scotland. Overview of the National Health Service in Scotland. Edinburgh: Audit Scotland, 2003. www.audit-scotland.gov.uk publications/pdf/03or01ag.pdf (accessed $10 \mathrm{Apr} 2003$ ).

23 County Durham and Darlington NHS Health Authority. Inpatien waiting list and outpatient waiting times report. October 2001 www.durham.nhs.uk/pubs/papers/Minutes0302.pdf (accessed $10 \mathrm{Apr}$ 2003).

(Accepted 21 March 2003) 